\title{
DETERMINATION OF CYCLODEXTRINS BY CAPILLARY LIQUID CHROMATOGRAPHY WITH INDIRECT CONDUCTIMETRIC DETECTION
}

\author{
Toyohide Takeuchi", Anang Sedyohutomo, Lee Wah Lim \\ Department of Chemistry, Faculty of Engineering, \\ Gifu University, 1-1 Yanagido, Gifu 501-1193, Japan \\ *Corresponding author. Tel.: +81 58293 2806; fax: +81 582932806. \\ email: take-t@gifu-u.ac.jp (Toyohide Takeuchi).
}

\begin{abstract}
Cyclodextrins (CDs) contained in a bottled Japanese tea and a wasabi (Japanese horseradish) paste were determined by capillary liquid chromatography (LC) with indirect conductimetric detection based on dilution of the mobile phase due to the analytes. High electrical conductivity background was maintained by addition of $5 \mathrm{mM}$ sodium nitrate in the mobile phase, and the analytes were visualized by decreases in the background when they eluted. The dynamic reserve, defined as the ratio of the background to its noise level, achieved under the present conditions was $1.7 \times 10^{5}$, which was much larger than that achieved by UV absorption detection. This means that indirect conductimetric detection gave better sensitivity than indirect UV absorption detection. A capacitively coupled contactless conductivity detector was convenient to monitor the effluents from capillary columns with minimum extra-column band broadening. The signals as negative peaks were linear to the concentration of the analytes, and the concentration detection limits achieved at $S / N=3$ were $0.02,0.05$ and $0.02 \%(\mathrm{w} / \mathrm{v})$ for $\alpha-\beta$ - and $\gamma-\mathrm{CD}$, respectively, corresponding to the mass detection limits of 30-75 ng for $0.15 \mu \mathrm{L}$ injection. The present detection method is not selective but universal, and it is useful in capillary LC when analytes have neither chromophore nor fluorophore groups.
\end{abstract}

Keywords: Capillary liquid chromatography, Indirect conductimetric detection, Capacitively coupled contactless conductivity detector, Cyclodextrins

\section{REFERENCES}

1. Y. Kubota, M. Fukuda, K. Ohtsuji, K. Koizumi, Microanalysis of $\beta$-cyclodextrin and glucosyl- $\beta$-cyclodextrin in human plasma by high-performance liquid chromatography with pulsed amperometric detection, Analytical Biochemistry, 201, 99-102, (1992).

2. M. Fukuda, Y. Kubota, A. Ikuta, K. Hasegawa, K. Koizumi, Microanalyses of $\beta$-cyclodextrin and glucosyl- $\beta$-cyclodextrin in biological matrixes by highperformance liquid chromatography with pulsed amperometric detection, Analytical Biochemistry, 212, 289-291, (1993).

3. L. C. Short, J. A. Syage, Electrospray photoionization (ESPI) liquid chromatography/mass spectrometry for the simultaneous analysis of cyclodextrin and pharmaceuticals and their binding interactions, Rapid Communications in Mass Spectrometry, 22, 541-548, (2008).

4. I. Caron, C. Elfakir, M. Dreux, Advantages of evaporative light scattering detection for the purity control of commercial cyclodextrins, J. of Liquid Chromatography \& Related Technologies, 20, 1015-1035, (1997).

5. M. Agueeros, M. A. Campanero, J. M. Irache, Simultaneous quantification of different cyclodextrins and Gantrez by HPLC with evaporative light scattering detection, $J$. of Pharmaceutical and Biomedical Analysis, 39, 495-502, (2005).

6. M. Pumera, I. Jelínek, J. Jindřich, P. Coufal, J. Horský, Determination of cyclodextrin content using periodate 
oxidation by capillary electrophoresis, $J$. of Chromatography A, 891, 201-206, (2000).

7. H. W. Frijlink, J. Visser, B. F. H. Drenth, Determination of cyclodextrins in biological fluids by high-performance liquid chromatography with negative colorimetric detection using post-column complexation with phenolphthalein, $J$. of Chromatography B: Biomedical Sciences and Applications, 415, 325-333, (1987).

8. T. Takeuchi, T. Miwa, Liquid chromatography of cyclodextrins with photometric detection of phenolphthalein inclusion complexes, Chromatographia, 38, 453-455, (1994).

9. E. Munaf, T. Takeuchi, T. Miwa, Visualization of cyclodextrins via complexation with iodine in microcolumn liquid chromatography, Analytica Chimica Acta, 418, 175-179, (2000).

10. T. Hiroi, J.-Y. Jin, T. Takeuchi, Photometric detection of cyclodextrins in liquid chromatography by using iodine generated electrochemically in-situ, Analytical and Bioanalytical Chemistry, 381, 1089-1094, (2005).

11. S. G. Penn, R. W. Chiu, C. A. Monning, Separation and analysis of cyclodextrins by capillary electrophoresis with dynamic fluorescence labelling and detection. $J$. of Chromatography A, 680, 233-241, (1994).

12. H. Wei, S. F. Y., Li, Capillary electrophoretic analysis of cyclodextrins with dynamic fluorescence labeling and detection, J. of Chromatography A, 800, 333-338, (1998).

13. T. Takeuchi, Y. Kitamaki, T. Miwa, Fluorimetric detection of cyclodextrins via complexation with fluorescence probe in microcolumn liquid chromatography, $J$. of Microcolumn Separation, 13, 19-23, (2001).

14. T. Takeuchi, Capillary columns in liquid chromatography, Analytical and Bioanalytical Chemistry, 375, 26-27, (2003).

15. S.-I. Mho, E. S. Yeung, Detection method for ion chromatography based on doublebeam laser-excited indirect fluorometry, Analytical Chemistry, 57, 2253-2256, (1985).

16. T. Takeuchi, D. Ishii, Indirect photometric detection of alcohols in micro highperformance liquid chromatography, $J$. of Chromatography, 393, 419-425, (1987).

17. T. Takeuchi, A. Sedyohutomo, L. W. Lim, Indirect Detection of ethylene glycol oligomers using a contactless conductivity detector in capillary liquid chromatography, Analytical Sciences, 25, 851-854, (2009).

18. W. S. Law, P. Kubáň, L. L. Yuan, J.H. Zhao, S. F. Y. Li, P. C. Hauser, Determination of tobramycin in human serum by capillary electrophoresis with contactless conductivity detection, Electrophoresis, 27, 1932-1938, (2006).

19. M. Petsch, B. X. Mayer-Helm, R. Sauermann, C. Joukhadar, E. Kenndler, Capillary electrophoresis analysis of fosfomycin in biological fluids for clinical pharmacokinetic studies, Electrophoresis, 25, 2292-2298, (2004).

20. M. Pumera, I. Jelínek, J. Jindřich, Determination of cyclodextrins and their derivatives by capillary electrophoresis with indirect UV and conductivity detection, Fresenius' Journal of Analytical Chemistry, 369, 666-669, (2001).

21. A. Z. Carvalho, J. A. F. da Silva, C. L. do Lago, Determination of mono- and disaccharides by capillary electrophoresis with contactless conductivity detection, Electrophoresis, 24, 2138-2143, (2003).

22. E. Baltussen, R. M. Guijt, G. van der Steen, F. Laugere, S. Baltussen, G. W. K. van Dedem, Considerations on contactless conductivity detection in capillary electrophoresis, Electrophoresis, 23, 28882893, (2002).

23. I. Surowiec, I. Kaml, E. Kenndler, Analysis of drying oils used as binding media for objects of art by capillary electrophoresis with indirect UV and conductivity detection, $J$. of Chromatography A, 1024, 245-254, (2004).

24. T. Takeuchi, D. Ishii, High-performance micro packed flexible columns in liquid chromatography, J. of Chromatography, 213, 25-32, (1981).

25. T. Takeuchi, M. Murayama, D. Ishii, Indirect detection of cyclodextrins in Micro-HPLC, J. of High Resolution Chromatography, 13, 69-70, (1990). 